\title{
Physically adjusted neutral detergent fiber system for lactating dairy cow rations. II: Development of feeding recommendations
}

\author{
Robin R. White, ${ }^{*}$ Mary Beth Hall, $†$ Jeffrey L. Firkins, $\ddagger$ and Paul J. Kononoff ${ }^{1}$ \\ *Department of Animal and Poultry Science, Virginia Tech, Blacksburg 24060 \\ †US Dairy Forage Research Center, Madison, WI 53706 \\ ‡Department of Animal Sciences, The Ohio State University, Columbus 43210 \\ §Department of Animal Science, University of Nebraska, Lincoln 68583-0908
}

\section{ABSTRACT}

The objective of this work was to leverage equations derived in a meta-analysis into an ensemble modeling system for estimating dietary physical and chemical characteristics required to maintain desired rumen conditions in lactating dairy cattle. Given the availability of data, responsiveness of ruminal $\mathrm{pH}$ to animal behaviors, and the chemical composition and physical form of the diet, mean ruminal $\mathrm{pH}$ was chosen as the primary rumen environment indicator. Physically effective fiber (peNDF) is defined as the fraction of neutral detergent fiber (NDF) that stimulates chewing activity and contributes to the floating mat of large particles in the rumen. The peNDF of feedstuffs is typically estimated by multiplying the NDF content by a particle size measure, resulting in an estimated index of effectiveness. We hypothesized that the utility of peNDF could be expanded and improved by dissociating NDF and particle size and considering other dietary factors, all integrated into a physically adjusted fiber system that can be used to estimate minimum particle sizes of TMR and diet compositions needed to maintain ruminal $\mathrm{pH}$ targets. Particle size measures of TMR were limited to those found with the Penn State particle separator (PSPS). Starting with specific diet characteristics, the system employed an ensemble of models that were integrated using a variable mixture of experts approach to generate more robust recommendations for the percentage of dietary DM material that should be retained on the 8-mm sieve of a PSPS. Additional continuous variables also integrated in the physically adjusted fiber system include the proportion of material (dry matter basis) retained on the 19- and 8-mm sieves of the PSPS, estimated mean particle size, the dietary concentrations of forage, forage NDF, starch, and NDF,

Received February 20, 2017.

Accepted August 7, 2017.

${ }^{1}$ Corresponding author: pkononoff2@unl.edu and ruminally degraded starch and NDF. The system was able to predict that the minimum proportion of material (dry matter basis) retained on the 8-mm sieve should increase with decreasing forage NDF or dietary NDF. Additionally, the minimum proportion of dry matter material on the 8-mm sieve should increase with increasing dietary starch. Results of this study agreed with described interrelationships between the chemical and physical form of diets fed to dairy cows and quantified the links between NDF intake, diet particle size, and ruminal $\mathrm{pH}$. Feeding recommendations can be interpolated from tables and figures included in this work.

Key words: ensemble models, particle size, effective fiber, ruminal $\mathrm{pH}$

\section{INTRODUCTION}

The NDF component of feed has 2 important nutritional elements of interest. The first is the extent to which it is degraded in the rumen (Robinson and McQueen, 1997), because it is made up of both potentially degradable NDF and undegradable NDF fractions (Harvatine et al., 2002). The second has been termed physically effective NDF (peNDF), which is defined as the extent to which the physical structure of fiber stimulates chewing and contributes to the floating mat of large particles in the rumen (Mertens, 1997). Both degradability and physical effectiveness influence ruminal pH (Allen, 1997). The peNDF content of individual feedstuffs has been estimated by multiplying the NDF concentration of a feed by the proportion of material retained on a 1.18- $\mathrm{mm}$ sieve determined using vertical dry sieving methods or by multiplying by the actual NDF content of the retained material (Mertens, 1997). The multiplication of particle size by feed composition makes peNDF an interaction term with an apparent implicit assumption that the 2 factors are linked, independent of the individual factors. In contrast with dry sieving, the Penn State particle separator (PSPS; 
Lammers et al., 1996; Kononoff et al., 2003) is more commonly used on farms to estimate the particle size of TMR. Several investigators have estimated peNDF as the NDF concentration of a TMR multiplied by the proportion of material retained on each or any of the sieves used in the PSPS (19-, 8-, and 1.18-mm; Einarson et al., 2004; Yang and Beauchemin, 2006; Zebeli et al., 2008, 2012); these peNDF values were used to evaluate effects of these fractions on ruminal $\mathrm{pH}$. Although the Dairy NRC (2001) did not include recommendations for peNDF, it did note that quantitative measures of particle size are needed and, if developed, should improve fiber recommendations for dairy cows.

The factors affecting ruminal $\mathrm{pH}$ and its role on ruminal fiber digestibility and microbial growth have been described (Firkins, 2010); however, each factor is typically evaluated when all other factors are held constant, often evaluated in vitro, which generally leaves out the various interactions that occur in vivo. Furthermore, models of the rumen environment are limited by data uncertainty because rumen conditions are also difficult to observe accurately (Sarhan and Beauchemin, 2015). Finally, identifying data sets with sufficient independent variation in all key independent variables to accurately derive parameter estimates is challenging. Overcoming this uncertainty requires evaluation of response surfaces that overlap multiple dimensions, and no single study can possibly evaluate all of these dimensions simultaneously. Interestingly, these challenges are similar to those inherent to weather forecasting models (Meier et al., 2014). To overcome data and model limitations in weather forecasting models, climatological researchers have employed ensemble modeling approaches to generate robust predictions of weather patterns as affected by various driving forces (Meier et al., 2014; Pollard et al., 2016). Ensemble models aggregate predictions from multiple different models to yield a mean and range of responses. Compared with individual models, ensemble approaches have advantages in probabilistic event modeling because they provide more reliable predictions of events, estimate confidence in the reliability of those predictions, and are less likely to generate systematic errors (Ebert, 2001). Rather than forcing integration of all models over an entire range of conditions, such that the full range has areas of instability, the ensemble approach uses a mixture of expert algorithms intelligently to integrate equations with varying weighting factors over the entire range of conditions. Therefore, an ensemble modeling approach (Roebber et al., 2004) was chosen to generate robust means and confidence intervals to describe the need for particle size, fiber, and other dietary components in diets for lactating cows. Compared with individual models, an ensemble approach will have improved utility, particularly in situations where minimal data are available for equation development (Polikar, 2006).

The objective of our work was to leverage equations derived in a meta-analysis (White et al., 2017) into a multidimensional system for estimating dietary physical and chemical characteristics required to maintain desired rumen conditions. Given the responsiveness of ruminal $\mathrm{pH}$ to animal behaviors and the chemical composition and physical form of the diet (Allen, 1997; White et al., 2017), mean ruminal $\mathrm{pH}$ was chosen as the indicator to describe whether the diet supported the desired ruminal characteristics. This indicator was chosen because it was frequently reported in many of the studies included in our data set, but it should be noted that other measures that were rarely reported, such as minimum or maximum $\mathrm{pH}$, time under 5.8 , or area under the curve of $\mathrm{pH}$ measures taken over time (Danscher et al., 2015), may serve as better indicators of problematic rumen conditions. Nonetheless, under varying dietary conditions, we tested adequacy of model combinations to predict mean ruminal $\mathrm{pH}$. Because model combinations may be dependent upon diet situations, we used the ensemble modeling approach to enable differential weighting of model predictions to generate description of diet effect. We hypothesized that the utility of peNDF could be expanded and improved by dissociating NDF and particle size and considering other dietary factors of the entire diet, all integrated into a physically adjusted fiber (paNDF) system that can be used to estimate minimum particle sizes of TMR and diet compositions needed to maintain varying ruminal $\mathrm{pH}$ targets under the range of dietary conditions experienced by dairy cattle in North America. Although development and simulation of the paNDF system was conducted in R v. 3.4.0 (Foundation for Statistical Computing, Vienna, Austria), the system of equations is simple enough to be implemented in any computational framework, including spreadsheet-based software such as Microsoft Excel (Microsoft Corporation, Redmond, WA).

\section{MATERIALS AND METHODS}

White et al. (2017) generated equations describing the effects of dietary physical and chemical characteristics on DMI, eating activity, rumination activity, and ruminal $\mathrm{pH}$. Our approach to integrate these equations allowed us to test and detect small effects of dependent variables while also including research that spans both controlled and noncontrolled factors, such as basal plane of nutrition (St-Pierre, 2007). To avoid confusion between equations referenced from White et al. 
(2017) and equations derived in our work, the equation numbers from White et al. (2017) have been converted to alphabetical identifiers $(\mathrm{A}=1, \mathrm{~B}=2, \mathrm{C}=3$, and so on), whereas the equations used in the current work use numeric identifiers listed to the right of each equation.

In the current study, a target mean ruminal $\mathrm{pH}$ was set for our exercise (target $\mathrm{pH}$ can be adjusted using our approach). The remaining models were then used to develop feeding recommendations for particle size and diet composition using an ensemble modeling approach. The ensemble was trained against the available data and used to simulate recommendations for forage NDF (fNDF) and the proportion of material retained on the 8-mm sieve (DM basis) of the PSPS (Kononoff et al., 2003). Model behavior was evaluated in comparison to data from published studies and widely understood relationships between variables (i.e., starch decreases rumen $\mathrm{pH}$ )

\section{Testing Model Adequacy}

As described in White et al. (2017), substantial challenges exist in selecting ideal models of DMI, rumination time, and rumen $\mathrm{pH}$ due to differences in the numbers of treatment means used for evaluation. To more objectively select ideal models, the data were subset so only treatments that could be predicted using all available models were included. All model combinations $(8$ DMI models $\times 8$ rumination time models $\times 8 \mathrm{pH}$ models) were tested for their ability to predict rumen $\mathrm{pH}$. The models were ranked based on the concordance correlation coefficient (Lin, 1989), a common metric of model precision and accuracy. The model combination with the highest concordance correlation coefficient where all supporting models (DMI, rumination time, and rumen $\mathrm{pH}$ ) were predicted on the same basis (DM or as-fed; AF) was used to select between DM and $\mathrm{AF}$ predictions. The best combination of models when compared against this common data set was comprised of DM measurements.

After selecting the DM models for further testing, available data that could be used to predict rumen $\mathrm{pH}$ were subset into a variety of scenarios. Scenarios included dietary characteristics such as low and high starch, low and high forage, low and high fNDF, low and high ADF-to-NDF ratio, and low and high diet NDF. The ADF-to-NDF ratio was included as an indirect measure of forage class (e.g., grass, legume, and so on; White et al. 2017) and fragility (Grant, 2010). Assuming a log-normal distribution, estimated mean particle size (MPS) was determined according to the calculations described by Waldo et al. (1971) using linear regression of the normal inverse of cumulative proportion
Table 1. Range of variables used in model system

\begin{tabular}{lccc}
\hline Variable & Mean & $-1 \mathrm{SD}$ & +1 SD \\
\hline NDF, \% TMR DM & 35 & 30 & 39 \\
Starch, \% TMR DM & 25 & 13 & 36 \\
fNDF, \% TMR DM & 19 & 12 & 26 \\
ADF/NDF, \%/\% & 0.63 & 0.37 & 0.89 \\
Forage percent, \% TMR DM & 46 & 36 & 56 \\
Wet forage (silage), \% TMR DM & 30 & 11 & 49 \\
Dry forage (hay), \% TMR DM & 10 & 0 & 23 \\
\hline
\end{tabular}

${ }^{1} \mathrm{fNDF}=$ forage NDF contained in TMR.

of particles retained on 19-, 8-, and (when available) 1.18-mm sieves of the PSPS versus the logarithm (base 10) of screen size, solving for $y=0$; the standard deviation (SD) of MPS was calculated as the inverse of the slope. Cutoffs for data inclusion (low or high) were at $1 \mathrm{SD}$ above or below the mean for any given variable. The SD and mean of all variables from White et al. (2017) are presented in Table 1. The top-ranked model combination varied across different scenarios, suggesting that different model combinations were better at representing diets with differing characteristic chemical composition. The wide variety of ideal models was not surprising, given the large differences in data among studies used to derive the different models.

\section{Combining Models with Differing Skills to Create an Ensemble}

The ensemble developed here used a parallel calculation approach with a mixture of experts integration (Figure 1). A mixture of experts model is a system composed of several models, each of which is trained (see process below) to handle a subset of the complete data set. In our case, the various ideal model combinations identified for the different dietary scenarios of interest are designated as these various experts. As listed in Tables 2 and 3, DMI models A and E, rumination time model $\mathrm{C}$, and $\mathrm{pH}$ models $\mathrm{B}$ and $\mathrm{D}$ were the equations used. These equations were grouped to provide experts for low and high $\mathrm{pH}$, low and high fNDF, low and high diet NDF, low and high ADF-to-NDF ratio, and low and high forage, which were the dietary characteristics remaining after backward elimination of potential parameters (White et al., 2017).

By establishing the proportion of material retained on the 19-mm sieve (which can be adjusted), each system of equations was used to predict the proportion of material retained on the 8-mm sieve for each data point available to meet the desired $\mathrm{pH}$ goal. An algebraic solution to the system is infeasible because the percentage of DM retained on the 8-mm sieve was a component used to calculate estimated MPS; instead, an optimiza- 


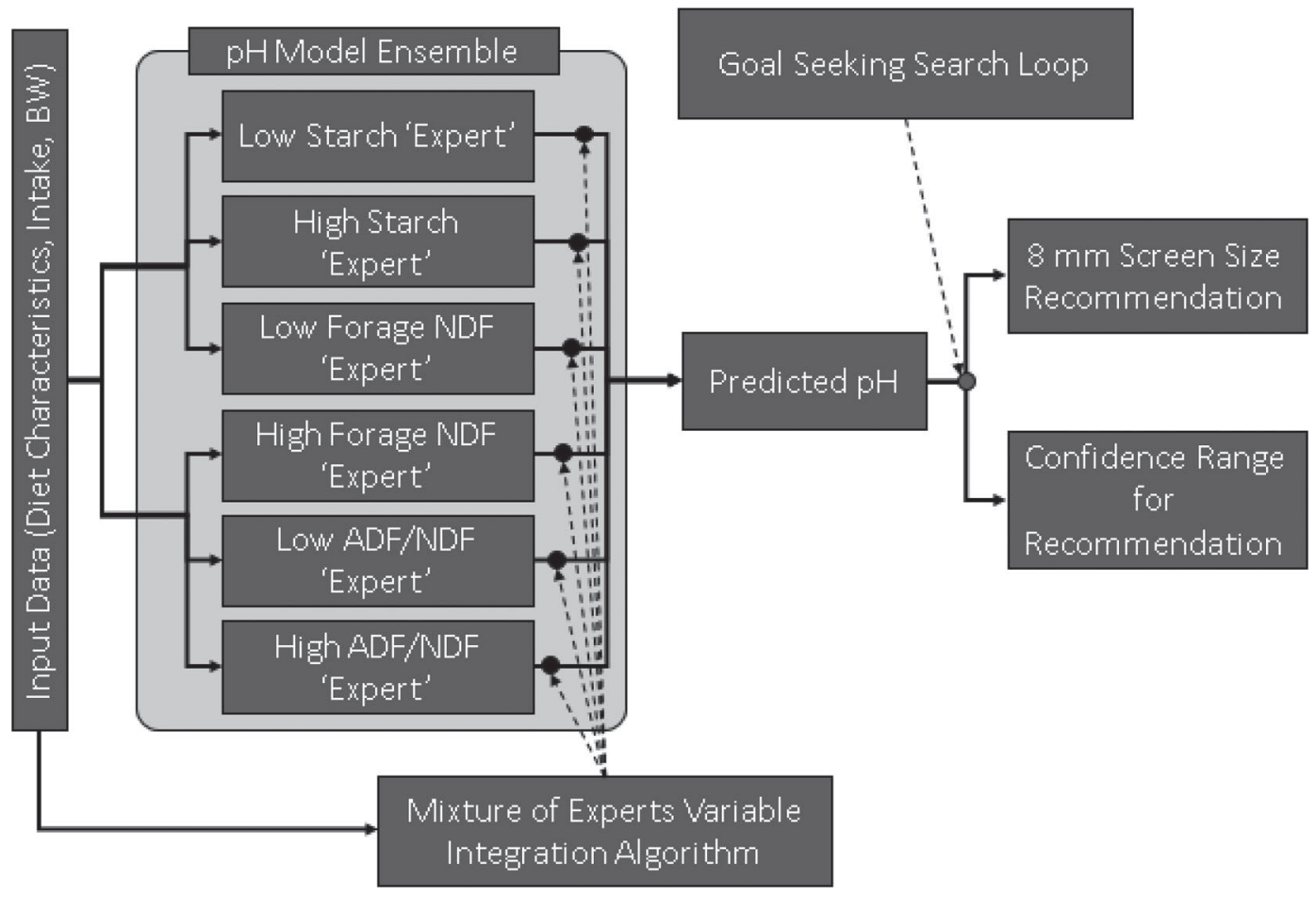

Figure 1. Depiction of strategy to estimate mean and confidence range of $\mathrm{pH}$ responses estimated by the model ensemble. Various expert models are identified (high vs. low starch) and $\mathrm{pH}$ is estimated with all expert models individually. The weighted mean of the predicted $\mathrm{pH}$ is estimated based on dietary composition using the variable mixture of experts' integration algorithm. The confidence range is estimated based on the minimum and maximum predictions of the ensemble.

tion approach was used. Golden section search (Tsai et al., 2010) and successive parabolic interpolation (Jarratt, 1967) were used to identify potential values of the percentage of DM material retained on the 8-mm sieve that generated the measured $\mathrm{pH}$ prediction. The resultant level of the $\mathrm{pH}$ prediction and the estimated

Table 2. Comparison of model rankings ${ }^{1}$ when evaluated against data sets with different potential causes of low $\mathrm{pH}$

\begin{tabular}{|c|c|c|c|c|c|c|c|c|c|}
\hline \multirow[b]{2}{*}{ Data type } & \multirow[b]{2}{*}{ Response variable } & \multicolumn{8}{|c|}{ Model $^{2}$} \\
\hline & & $\mathrm{A}$ & $\mathrm{B}$ & $\mathrm{C}$ & $\mathrm{D}$ & $\mathrm{E}$ & $\mathrm{F}$ & G & $\mathrm{H}$ \\
\hline \multirow[t]{3}{*}{ Low pH } & DMI & 2 & & 4 & & 1 & & 3 & \\
\hline & Rumination time & 1 & 7 & 4 & 2 & 1 & 5 & 3 & 6 \\
\hline & Rumen pH & & 2 & & 1 & & & & \\
\hline \multirow[t]{3}{*}{ Low $\mathrm{fNDF}^{3}$} & DMI & 2 & & 4 & & 3 & & 1 & \\
\hline & Rumination time & 6 & 1 & 8 & 4 & 5 & 3 & 7 & 2 \\
\hline & Rumen pH & & 2 & & 1 & & & & \\
\hline \multirow[t]{3}{*}{ Low NDF } & DMI & 2 & & 4 & & 1 & & 3 & \\
\hline & Rumination time & 8 & 7 & 3 & 4 & 1 & 5 & 2 & 6 \\
\hline & Rumen pH & & 1 & & 2 & & & & \\
\hline \multirow{3}{*}{ Low forage } & DMI & 4 & & 2 & & 1 & & 3 & \\
\hline & Rumination time & 8 & 6 & 2 & 5 & 4 & 7 & 1 & 3 \\
\hline & Rumen pH & & 2 & & 1 & & & & \\
\hline
\end{tabular}

${ }^{1}$ Lower number within row of DMI, rumination time, and ruminal $\mathrm{pH}$ indicates better fit within a data type. For example, the best combination of models for low $\mathrm{pH}$ would be DMI model 5 , rumination time model 1 or 5 , and rumen $\mathrm{pH}$ model 1.

${ }^{2}$ Models are specified as A through $\mathrm{H}$ and correspond to equations 1 through 8 presented in White et al. (2017), where $\mathrm{A}=1, \mathrm{~B}=2, \mathrm{C}=3$, and so on. Alphabetical equation designees were used to avoid having multiple numeric equation identifiers.

${ }^{3} \mathrm{fNDF}=$ forage NDF. 
Table 3. Models developed by White et al. (2017) during ensemble model training (units of all parameters on a DM basis) and used to generate feeding recommendations

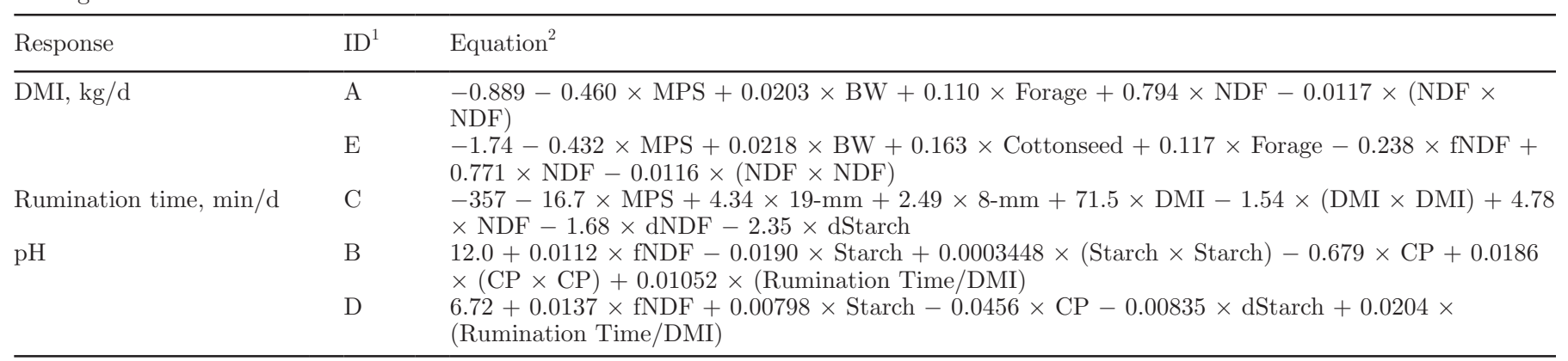

${ }^{1}$ Models are specified as $\mathrm{A}$ through $\mathrm{E}$ and correspond to equations 1 through 8 presented in White et al. $(2017)$, where $\mathrm{A}=1, \mathrm{~B}=2, \mathrm{C}=3$, and so on. Alphabetical equation designees were used to avoid having multiple numeric equation identifiers.

${ }^{2}$ MPS $=$ estimated mean particle size from Penn State particle separator data in $\mathrm{mm}$; BW $=\mathrm{kg}$. All dietary concentrations are on a DM basis: forage $=\%$ of forage in the TMR; NDF $=\% \mathrm{NDF}$ in the TMR; cottonseed $=\%$ of cottonseed in the TMR; fNDF $=\%$ of forage NDF in the TMR $; 19-\mathrm{mm}=\%$ of TMR retained on the $19-\mathrm{mm}$ sieve of the Penn State particle separator; $8-\mathrm{mm}=\%$ of TMR retained on the 8-mm sieve of the Penn State particle separator; DMI $=\mathrm{kg} / \mathrm{d} ; \mathrm{dNDF}=$ rumen-degraded NDF as estimated by White et al. $(2017)$; dStarch $=$ rumendegraded starch as estimated by White et al. (2016); starch $=\%$ of starch in the TMR; CP $=\%$ of CP in the TMR; rumination time $=$ time spend ruminating, $\min / \mathrm{d}$.

percentage of DM material on the 8-mm sieve were recorded for each of 85 available treatment means. A sequential averaging training approach was then used to pair models with different skillsets based on dietary characteristics. The low and high fNDF experts predictions of the proportion of DM retained on the 8-mm sieve were averaged following (Eq. 1):

$$
\begin{gathered}
W_{E, C, D}=\left(1-k_{\text {Starch }} \times \frac{\text { Starch }}{\text { Forage }}\right), \\
W_{A, C, B}=k_{\text {Starch }} \times \frac{\text { Starch }}{\text { Forage }}, \\
\text { Expert }_{\text {Starch }}=8-\mathrm{mm}_{E, C, D} \times W_{E, C, D} \\
+8-\mathrm{mm}_{A, C, B} \times W_{A, C, B},
\end{gathered}
$$

where $W_{E, C, D}$ was the weight assigned to the predicted $\mathrm{DM}$ material on the 8-mm sieve from DMI equation $\mathrm{E}$, rumination time equation $\mathrm{C}$, and $\mathrm{pH}$ equation $\mathrm{D}$ $\left(8-\mathrm{mm}_{E, C, D}\right) ; W_{A, C, B}$ was the weight assigned to the predicted DM material retained on the $8-\mathrm{mm}$ sieve from DMI equation $\mathrm{A}$, rumination time equation $\mathrm{C}$, and $\mathrm{pH}$ equation B $\left(8-\mathrm{mm}_{A, C, B}\right)$; Starch is dietary starch percentage (\% of DM); Forage is dietary forage percentage (\% of DM); Expert ${ }_{\text {Starch }}$ was the generated predicted percentage of DM on the 8-mm sieve; and $k_{\text {starch }}$ is the fitted constant to adjust the weight of the models based on the dietary ratio of starch to forage.

The same approach was used to generate expert predictions that accounted for diet NDF percentage (Eq. 2)

$$
\begin{gathered}
W_{E, C, B}=\left(1-k_{\mathrm{NDF}} \times \mathrm{NDF}\right), \\
W_{A, C, D}=k_{\mathrm{NDF}} \times \mathrm{NDF}, \\
\operatorname{Expert}_{\mathrm{NDF}}=8-\mathrm{mm}_{E, C, B} \times W_{E, C, B} \\
+8-\mathrm{mm}_{A, C, D} \times W_{A, C, D},
\end{gathered}
$$

where the differing letter subscripts represent the model letter designation for DMI, rumination time, and $\mathrm{pH}$, respectively; NDF is dietary NDF percentage (\% of $\mathrm{DM}) ; k_{\mathrm{NDF}}$ is the fitted constant to adjust the weight of the models based on dietary NDF, and Expert ${ }_{\mathrm{NDF}}$ is the expert prediction for the percentage of DM material on the 8-mm sieve that accounts for dietary NDF percentage. Equations generated for ADF-to-NDF ratio (Eq. 3) were

$$
\begin{gathered}
W_{E, C, D}=\left(1-k_{\mathrm{ADFNDF}} \times \frac{\mathrm{ADF}}{\mathrm{NDF}}\right), \\
W_{A, C, D}=k_{\mathrm{ADFNDF}} \times \frac{\mathrm{ADF}}{\mathrm{NDF}}, \\
\text { Expert }_{\mathrm{ADFNDF}}=8-\mathrm{mm}_{E, C, D} \times W_{E, C, D} \\
+8-\mathrm{mm}_{A, C, D} \times W_{A, C, D},
\end{gathered}
$$

where the differing letter subscripts represent the model letter designation for DMI, rumination time, and $\mathrm{pH}$, respectively; $\mathrm{ADF}$ is dietary $\mathrm{ADF}$ percentage (\% of $\mathrm{DM}), k_{\mathrm{ADFNDF}}$ is the fitted constant to adjust the weight of the models based on the dietary ratio of ADF to 
NDF, and Expert ${ }_{A D F N D F}$ is the expert prediction of the proportion of DM material that should be retained on the 8-mm sieve when adjusted for ADF-to-NDF ratio. Equations generated for fNDF (Eq. 4) were

$$
\begin{gathered}
W_{E, C, B}=\left(1-k_{\mathrm{fNDF}} \times \mathrm{fNDF}\right), \\
W_{A, C, B}=k_{\mathrm{fNDF}} \times \mathrm{fNDF}, \\
\operatorname{Expert}_{\mathrm{fNDF}}=8-\mathrm{mm}_{E, C, B} \times W_{E, C, B} \\
+8-\mathrm{mm}_{A, C, B} \times W_{A, C, B},
\end{gathered}
$$

where the differing letter subscripts represent the model letter designation for DMI, rumination time, and $\mathrm{pH}$, respectively; fNDF is dietary fNDF percentage $(\%$ of $\mathrm{DM}) ; k_{\mathrm{fNDF}}$ is the fitted constant to adjust the weight of the models based on dietary forage NDF; and Expert $_{\mathrm{fNDF}}$ is the expert prediction for the percentage of DM material that should be on the $8-\mathrm{mm}$ sieve to achieve the desired $\mathrm{pH}$ target that is sensitive to dietary fNDF.

A series of functions was then fit to average these predictions into a single estimate of the percentage of DM material on the 8-mm sieve

$$
\begin{gathered}
8-\mathrm{mm}_{\mathrm{fNDF}, \mathrm{ADFNDF}}=\text { Expert }_{\mathrm{fNDF}} \\
\times\left(k_{\mathrm{fNDF}, \mathrm{ADFNDF}} \times \text { Forage }\right)+\text { Expert }_{\mathrm{ADFNDF}} \\
\times\left(1-k_{\mathrm{fNDF}, \mathrm{ADFNDF}} \times \text { Forage }\right) \\
8-\mathrm{mm}_{\mathrm{NDF}, \text { Starch }}=\text { Expert }_{\mathrm{NDF}} \times\left(k_{\mathrm{NDF}, \text { Starch }} \times \text { Starch }\right) \\
+ \text { Expert }_{\mathrm{Starch}} \times\left(1-k_{\mathrm{NDF}, \text { Starch }} \times \text { Starch }\right), \\
8-\mathrm{mm}=\frac{8-\mathrm{mm}_{\mathrm{fNDF}, \mathrm{ADFNDF}}+8-\mathrm{mm}_{\mathrm{NDF}, \text { Starch }}}{2},
\end{gathered}
$$

where $8-\mathrm{mm}_{\mathrm{fNDF}, \mathrm{ADFNDF}}$ is the aggregated expert accounting for forage characteristics, $8-\mathrm{mm}_{\mathrm{NDF}, \mathrm{Starch}}$ is the aggregated expert accounting for diet NDF to starch ratio, and $8-\mathrm{mm}$ is the final prediction of the percentage of DM material that should be retained on the $8-\mathrm{mm}$ sieve to achieve the desired $\mathrm{pH}$. The various parameters for this weighting scheme were fitted simultaneously to data using the FME package of $\mathrm{R}$ v. 3.4.0. (R Core Team, 2014). The parameter estimates, standard errors and significance values are included in Table 4 .

\section{System Usage}

The resultant system of equations can be used to generate recommended percentages of DM material that should be on the 8-mm sieve of a PSPS to achieve a desired $\mathrm{pH}$ given a known DMI, dietary percentages of starch, ADF, NDF, fNDF, CP, forage, dry forage, wet forage, and percentage of DM in the diet retained on the 19-mm sieve. The percentage of DM on the $19-\mathrm{mm}$ sieve can and should vary with respect to the 8-mm sieve because, even though these sieve fractions are inversely correlated, the percentage of DM on the larger sieve influences ruminal mat consistency and rumination activity, thus interacting with smaller particles (see discussion in White et al., 2017). The first step in applying the system is to use an optimization algorithm to solve for the estimated percentage of material on the 8-mm sieve required to achieve the desired $\mathrm{pH}$ at the defined dietary conditions. The second step is to use the estimates and Eq. 1 to 5 to consolidate the predictions down to a single estimate of the recommended percentage of DM material on the 8-mm sieve. Although a fairly simple procedure, these calculations rely on the availability of an optimization algorithm. Although a more complex search was used in the derivation procedure, a simple exhaustive area search algorithm could easily be employed in the first step. This approach likely will use minimal additional computing time, as the available search space for the parameter is limited between 0 and $100 \%$ minus the percentage of

Table 4. Parameter estimates, SE, and significance values derived during ensemble model training

\begin{tabular}{llccr}
\hline $\begin{array}{l}\text { Equation } \\
\text { number }^{1}\end{array}$ & Parameter $^{2}$ & Estimate & $\mathrm{SE}^{3}$ & $P$-value \\
\hline 1 & $k_{\text {Starch }}$ & 0.699 & 0.345 & 0.046 \\
2 & $k_{\text {NDF }}$ & 0.0213 & 0.0033 & $<0.001$ \\
3 & $k_{\text {ADFNDF }}$ & 1.35 & 0.210 & $<0.001$ \\
4 & $k_{\text {fNDF }}$ & 0.0206 & 0.0101 & 0.012 \\
5 & $k_{\mathrm{fNDF}, \text { ADFNDF }}$ & 0.0120 & 0.0551 & 0.043 \\
& $k_{\mathrm{NDF}, \text { Starch }}$ & 0.0791 & 0.0312 & 0.013 \\
\hline
\end{tabular}

${ }^{1}$ Equation numbers are reflective of equations described in this work.

${ }^{2}$ Parameters are as defined in equations 1 to 5 and represent weighting factors used to calculate weighted averages of $\mathrm{pH}$ predictions made with the different expert models.

${ }^{3}$ Standard errors (SE) reflect variability around the mean parameter estimate. 
material on the 19-mm sieve; thus, it results in a fairly simple optimization problem that is virtually guaranteed to either converge on a global solution or, if it fails to converge, indicates that the $\mathrm{pH}$ can be achieved for all possible levels of material on the 8 -mm sieve as is often the case with very low $\mathrm{pH}$ cutoffs.

\section{Generating Feeding Recommendations}

Dietary recommendations for fNDF and the percentage of DM in the total diet that should be retained on the 8-mm sieve were generated for diets varying in starch, NDF, and by the proportion of DM retained on the 19-mm sieve of the PSPS; this was done while assuming a constant ADF-to-NDF ratio (0.63), dry forage percentage $(33 \% \times$ forage percentage), wet forage percentage $(67 \% \times$ forage percentage $)$, cow $\mathrm{BW}$ $(631 \mathrm{~kg})$, and CP $(16.5 \% \mathrm{DM})$. These constant values were selected for this example because they reflected the mean of the data in White et al. (2017). Starch, total NDF, and fNDF were allowed to range from 15 to 35,25 to 40 , and 10 to $30 \%$ of $\mathrm{DM}$, respectively. The percentage of diet DM retained on the $19-\mathrm{mm}$ sieve was assumed to be either 6,12 , or $18 \%$ (but could be changed to other values for a larger range of solutions). These ranges of all nutrients are rounded but reflect the mean $\pm 1 \mathrm{SD}$ of the distributions defined in the available data (Table 1) with some exceptions (starch, $\mathrm{NDF}$ ), from which the range was extended to better simulate diets with potentially problematic effects on ruminal $\mathrm{pH}$. The ensemble was used to predict the percentage of DM material on the 8 -mm sieve across a range of fNDF values for starch, NDF, and percentage of material on the 19-mm sieve.

Recommendations for the percentage of diet DM on the $8-\mathrm{mm}$ sieve were defined by identifying inflection points relative to fNDF. An inflection point was identified as any fNDF for which the second derivative changed by $20 \%$ or more compared with the previous fNDF value. In general, 2 inflection points were identified. One inflection point had high fNDF and a low percentage of DM material on the 8-mm sieve, and the other had low fNDF and a high percentage of DM material on the 8-mm sieve. Both inflection points and the average of the 2 points are presented to provide a range in recommendations representing tradeoffs between $\mathrm{fNDF}$ and the percentage of DM material on the 8 -mm sieve. In some cases, one or both inflection points were not identified within the allowable range of fNDF. In that case, the lowest- or highest-allowable fNDF was used for recommendation to better highlight continuous trends in prediction over the range of dietary inputs. Alternative strategies for coping with dietary input combinations that do not generate an inflection point include solving for the fNDF, which generates some maximum allowable percentage of material retained on the 8-mm sieve, or solving for the percentage of material retained on the $8-\mathrm{mm}$ sieve given a desired or target dietary fNDF.

\section{RESULTS AND DISCUSSION}

The proposed paNDF system generates feeding recommendations (Supplemental File S1; https://doi. org/10.3168/jds.2017-12766) for diet characteristics based upon computation, varying those requirements with respect to differing potential for a ruminal acid load and countering them for differing distributions of forage particle size as measured in a TMR (i.e., after potential particle size reduction in a mixer). This is somewhat of a departure from NRC (2001), in which a simple table (Table 4-3 from that source) from which minimum concentrations of fNDF, NDF, and NFC could be determined through interpolation. After that publication, the direct analysis of starch has replaced the calculation-based estimate of NFC (Hall, 2015). Additionally, the NRC table did not offer any recommendations regarding the estimated particle size of a TMR fed to lactating dairy cattle. Subsequent to the publication the Dairy NRC (2001), several research groups studied influences of the chemical and physical characteristics of TMR on lactating dairy cattle, including but not limited to studies in the United States in Wisconsin (Schwab et al., 2002; Krause and Combs, 2003; Leonardi et al., 2005), Pennsylvania (Kononoff and Heinrichs, 2003; Maulfair and Heinrichs, 2013; Kmicikewycz et al., 2015), New York (Dann et al., 2014; Farmer et al., 2014), and Michigan (Kammes and Allen, 2012); in Canada in Alberta (Yang and Beauchemin, 2006) and Manitoba (Einarson et al., 2004; Bhandari et al., 2008); as well as in Germany (Zebeli et al., 2008).

Although both particle size and fiber concentration of rations are known to stimulate chewing activity, agreement has not been reached on the best particle size metric to estimate the physical component of the TMR. This is because it is not clear which physical measure provides the most useful estimate of physiological responses (Zebeli et al., 2012). For example, Mertens (1997) suggested using particles $\geq 1.18 \mathrm{~mm}$ as estimated by dry sieving, and measures of particles retained on any or all of the sieves used by the PSPS (19, 8 , and $1.18 \mathrm{~mm}$ ) have also been evaluated (Einarson et al., 2004; Yang and Beauchemin, 2006). The present study is unique because it allowed the different measures of particle size based on sieve size or estimated mean particle size from only the PSPS to self-identify as optimal during the model building process. Despite 
the differences in accounting of particle size, our animal-based response variables were consistent with the concept of peNDF, particularly chewing activities and their subsequent influence on ruminal pH (Balch, 1971; Sudweeks et al., 1981; Mertens, 1997; Norgaard, 1989), but also extends current NRC (2001) recommendations for NDF to include information on particle size.

All particle size measures used in the paNDF system were determined with PSPS and reported on a DM basis. Although it was difficult to compare AF- and DM-based models from the full derivation data set due to largely differing numbers of available data for the 2 approaches (White et al., 2017), the ranking of different model combinations in the present work showed that the DM models performed better as a system when evaluated in comparison to the systems of AF models. As shown in Figure 1, the final model averaging parameters weighted the equations grouped by forage characteristics (fNDF and ADF-to-NDF ratio) and diet concentrate to forage indicators (diet concentrations of NDF and starch).

The extent to which the physical structure of the diet influences rumen conditions is, at least in part, through stimulation of chewing activity, which can respond distinctly between chewing during eating versus ruminating (White et al., 2017); Zebeli et al. (2012) identified the potential for optimizing, rather than providing just a minimum, peNDF by also depicting the role of ruminal fill to limit DMI with increasing particle size. A novel unification in our approach is that TMR particle size has roles to stimulate chewing during rumination versus eating that do not necessarily require peNDF (particle size multiplied by NDF) while still integrating effects of dietary chemical factors (such as starch and NDF) and their acidogenic potential. Thus, our quantitative findings provide a more comprehensive approach than previous efforts, as both TMR particle size and diet NDF influence both DMI and rumination time, in agreement with mechanistic expectations, and these factors in turn were integrated into a system that could be robustly related to observed ruminal $\mathrm{pH}$ in dairy cattle (Table 3 ).

\section{Evaluation of Model Behavior}

To evaluate model behavior, the ensemble model was used to predict recommended percentages of diet DM that should be retained on the $8-\mathrm{mm}$ screen to achieve a pH of either 6.1 or 6.0. Currently, agreement does not exist for the optimal ruminal $\mathrm{pH}$, but in this example 6.1 was chosen because it was the mean of the data set of White et al. (2017). A pH of 6.0 was also used because cellulolysis has been reported to be inhibited when ruminal $\mathrm{pH}$ is less than 6.0 (Mould et al., 1983; Shi and Weimer, 1992). In our study, this mean $\mathrm{pH}$ was associated with periods after feeding when $\mathrm{pH}$ was below 6.0 , but insufficient common metrics were provided to develop that concept. Above a mean $\mathrm{pH}$ of 6.2 was deemed unnecessary, and below 6.0 generated predictions with required large particle $(>8 \mathrm{~mm})$ percentages that were often infeasible $(19 \mathrm{~mm}$ $+8 \mathrm{~mm}>100)$. The 3 dietary characteristics in the model were dietary concentrations of NDF and starch and proportion of particles retained on a 19-mm screen. For each combination of these 3 factors and for each target $\mathrm{pH}$ (6.0 or 6.1), 3 recommendations for fNDF ( $\%$ DM) and percentage of dietary DM material retained on the 8-mm sieve were generated (Table 5). The first recommendation, low particle size, reflects the response surface inflection point where particle size is low but fNDF is high. The second recommendation, high particle size, reflects the response surface inflection point where particle size is high but fNDF is low. The final recommendation represents the average between these 2 inflection points and has moderate particle size and moderate fNDF. To illustrate these inflection points, Figure 2 was generated. In the top left graph of this figure depicting $6 \%$ of TMR DM retained on a $19-\mathrm{mm}$ screen and 15\% TMR DM starch, 2 inflection points are clearly visible. One occurs at approximately $16.0 \%$ fNDF, and the other at approximately $26.5 \%$ fNDF. This figure can be interpreted to suggest that ruminal $\mathrm{pH}$ can be maintained in a diet low in fNDF (16.0\%) by increasing the proportion of TMR (between 40 and $60 \%)$ retained on the $8-\mathrm{mm}$ sieve. Alternatively, when feeding a diet high in fNDF (26.6\%), a lower proportion of TMR $(<20 \%)$ retained on the $8-\mathrm{mm}$ sieve is needed. In practice, a true recommendation for the percentage of DM material on the 8-mm sieve should be based on the diet target fNDF and likely lies somewhere between these 2 inflection points. Increasing either fNDF or particle size near these ranges and as a means to increase chewing activity and ruminal $\mathrm{pH}$ has been observed experimentally (Yang and Beauchemin, 2007a, 2009); however, the effects of particle size are also influenced by the fermentability of the diet (Yang and Beauchemin, 2007b). A limitation of the peNDF system (Mertens, 1997) is that it did not account for differences in rumen fermentability, most notably rumen-degraded starch (Dijkstra et al., 2012), which is integrated into the current system. Rumen-degraded starch was robustly predicted across a variety of dairy diets (Roman-Garcia et al., 2016), but it might not capture specific effects of grain processing; hence, with more intensive processing, a user should navigate toward high particle size recommendations. It should also be noted that because 
estimates listed in Table 5 are generated from solutions stemming from a wide range values within each input, some extreme scenarios are implausible. For example, several cases are listed in which total ration NDF is less than fNDF, these cases are retained for illustrative purposes.

\section{Recommended Particle Size with Changes in fNDF, Diet Starch and NDF}

The particle size and fNDF feeding recommendations generated by the system are listed in Table 5 . The relationship between predicted $\mathrm{pH}$ and recommended particle size is shown in Figure 3. Models generated by White et al. (2017) identified several explanatory variables that are responsible for maintaining desired rumen conditions. As hypothesized, particle size, dietary concentrations of starch and NDF, rumen-degraded $\mathrm{NDF}$ and starch, fNDF, and ADF-to-NDF ratio were identified as key explanatory variables. Some caution should be exercised when interpreting this table because it does not account for the effects of increasing particle size and feed selection or sorting behavior (Greter and Devries, 2011; Maulfair and Heinrichs, 2013). Furthermore, compared with other laboratory scale methods such as the ASABE A424.1 standard (ASABE, 2007), the PSPS lacks precision but its portability and ease of use make it a frequently used tool by dairy nutritionists who, for practical reasons, may not follow best practices often descried from sieving methods. One such practice is that "...should material on the top sieve exceed $1 \%$ of the total sample mass, representative subsamples should be obtained from this [sieve] and measured manually." The analytical consequence of this is that the measure of MPS calculated from PSPS data would be less precise; thus, we must assume that all particles contribute to a normal distribution of particles, and that any error in estimating MPS is somewhat consistent across studies from which data will be applied. All but 1 study included in the database used to derive the equations had $>1 \%$ AF or DM material on the $19-\mathrm{mm}$ screen; this is normal in the use of PSPS.

The interrelationships of particle size with fNDF and dietary concentrations of starch and NDF are described in 3 key observations. First, as the percentage of DM material on the 19-mm sieve increases, the cutoff fNDF recommendations decrease, as do the recommended percentages of DM material retained on the $8-\mathrm{mm}$ sieve. This observation suggests that, at least to some extent, increasing particle size has similar effects on the animal as does increasing fNDF. This is consistent with experimental observations in which increasing particle size in diets low in fNDF have prevented ruminal $\mathrm{pH}$ from dropping as low as with diets with shorter particle size (Yang and Beauchemin, 2007b). Second, as dietary starch increases, the cutoff fNDF percentages increase, suggesting that more $\mathrm{fNDF}$ is required to achieve the same target $\mathrm{pH}$ as more starch is added to the diet. This relationship supports and advances the NRC (2001) guideline by replacing NFC with starch. When fed high concentrations of starch, resulting in the induction of SARA, dairy cattle exhibited a preference to consume larger particles, which is a behavior thought to be an animal-directed response to attenuate low ruminal pH (Keunen et al., 2002; Kmicikewycz and Heinrichs, 2015). The contribution of fNDF to the buffering of the rumen has been observed experimentally (Zebeli et al., 2008), but the explanation behind this response is not necessarily only related to increased saliva secretion. Allen (1997) suggested that this response is due to the stimulation of rumen motility and greater absorption of acids out of the rumen. Third, as the diet contains more NDF, the target fNDF and percentage of DM material on the 8-mm screen decrease. The positive effect of NDF on ruminal $\mathrm{pH}$ has been previously observed (Zebeli et al., 2008), though the replacement of fNDF with NDF from by-products has also been observed to have a depressing effect on ruminal $\mathrm{pH}$ (Zhu et al., 1997). Our database includes numerous studies that capture diets with traditional shifts in forage-toconcentrate ratio, but also more recent studies in which by-product NDF replaced forage, concentrate, or both; these data have been limiting in previous peNDF evaluations (Bradford and Mullins, 2012).

\section{Fragility and Particle Size Recommendations}

Fragility of a feed can be defined as the rate at which plant tissues contained in a feed particle are further fragmented into small particles (Kennedy et al., 1997; Grant, 2010). Although a laboratory method to measure forage fragility has been proposed (Farmer et al., 2014), its use has not been widely reported in the literature. As a result, the ratio of ADF to NDF was calculated and included here as an indirect measure of forage fragility (legumes have a higher ADF-to-NDF ratio than grasses, and corn silage is in between; see White et al., 2017). Because legumes have more fragile fiber than grasses and can be more easily fragmented (Kammes and Allen, 2012), legumes likely stimulate less rumination and salivary buffer production. It has been reported that rumination probably stimulates more saliva secretion per minute of chewing compared with eating (Beauchemin, 1991). In contrast, grasses have a higher content of hemicellulose (Van Soest, 1994), which crosslinks with lignin, may be less fragile, 


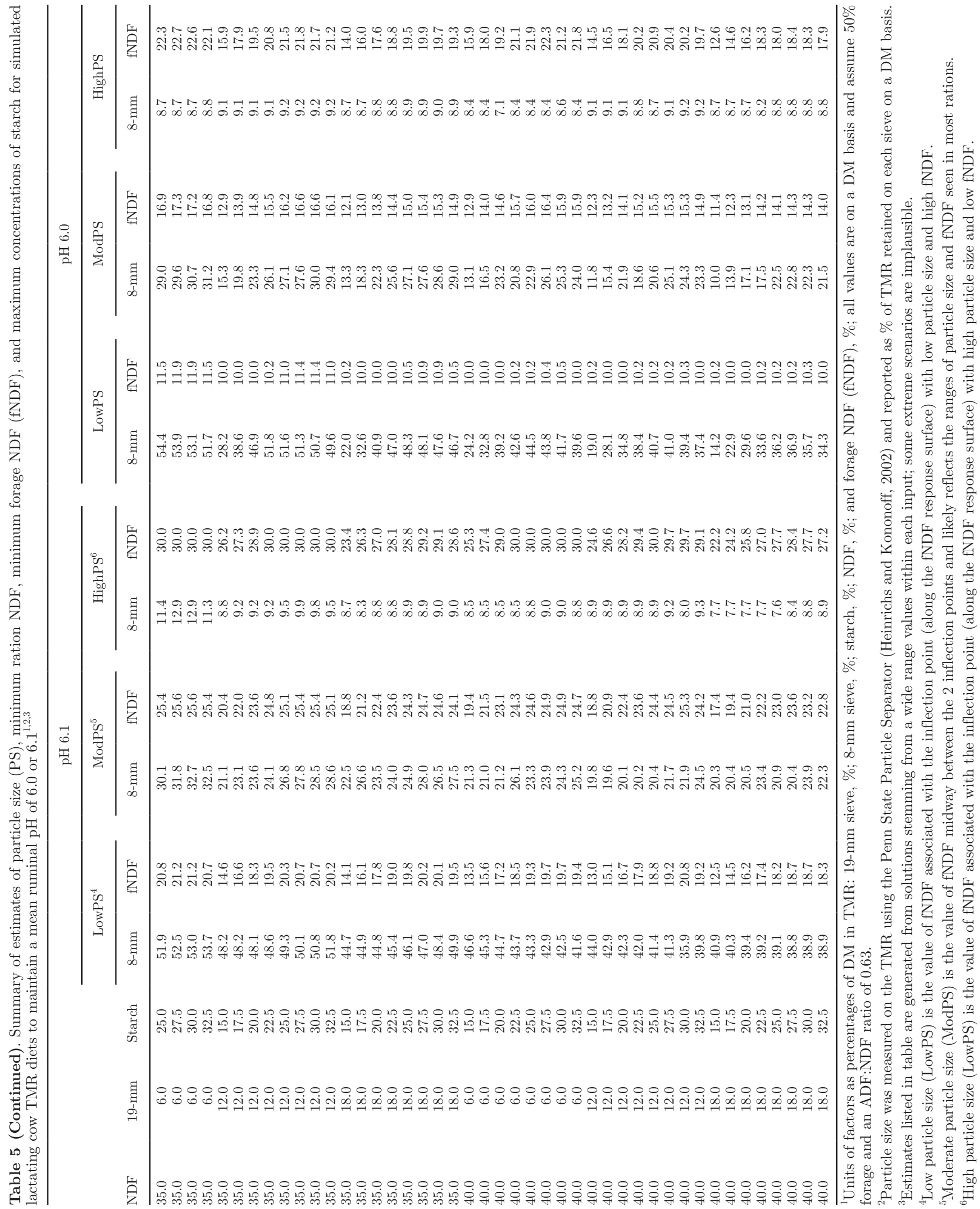




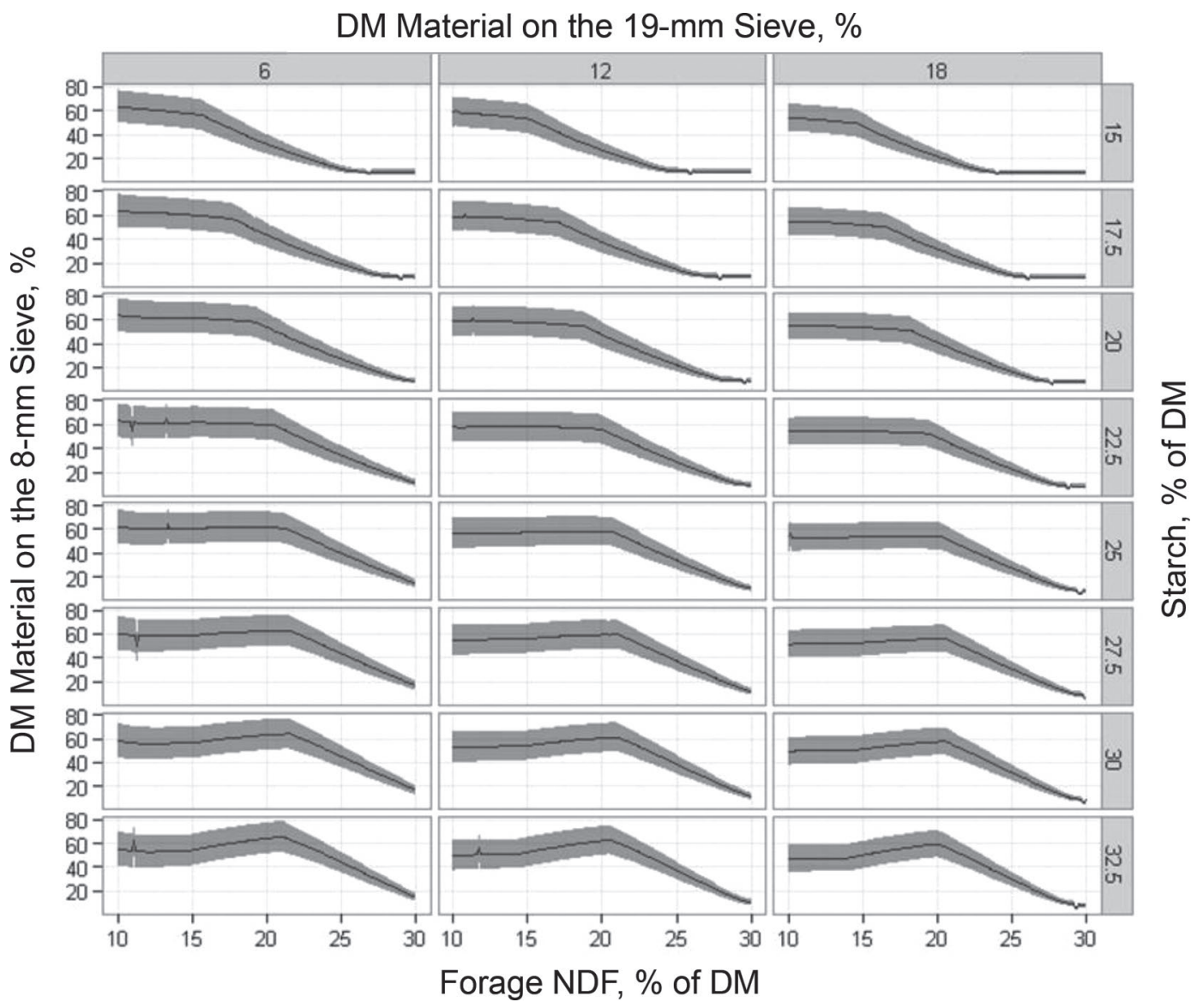

Figure 2. Response surfaces generated by the multimodel ensemble for a target $\mathrm{pH}$ of 6.1 . Curves were generated by iterating through the system of equations [equations listed in Table 3 from White et al. (2017) in combination with the mixture of experts' variable integration algorithm described in equations 1 through 5] for each combination of inputs. For some input combinations the optimization component of the variable integration algorithm did not perform well and small point-specific discontinuities were generated. Additionally, at high starch concentrations the behavior of the system at low forage NDF percentages appears contrary to expectations. These limitations of the model system are likely due to the limited data availability for derivation. Response surfaces reflect $30 \%$ diet NDF, $50 \%$ forage, and ADF:NDF of 0.63 .

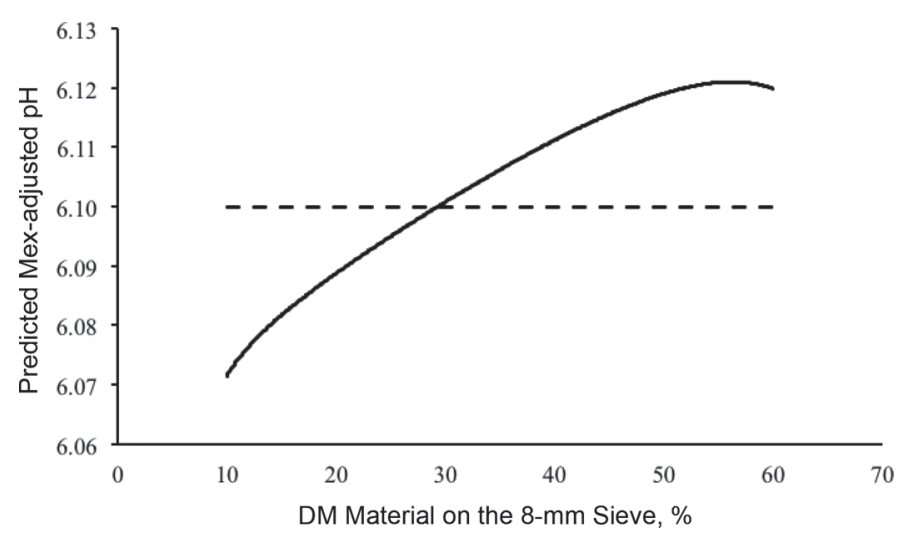

Figure 3. An example of the ensemble model's predicted influence of increasing the proportion of TMR retained on the 8-mm sieve of the Penn State Particle Separator on mean ruminal pH. For reference, the target $\mathrm{pH}$ of 6.1 is indicated by the horizontal dashed line. and might be more effective in stimulating chewing activity (Mertens, 1997). In contrast to Mertens (1997) and Zebeli et al. (2012), we included ADF-to-NDF ratio as an indirect measure of forage fragility and in an attempt to account for differences in forage species (Cotanch et al., 2008), and it remained in final models as a significant explanatory variable. The recommended percentage of dietary DM material on the 8-mm sieve associated with differing ADF-to-NDF ratio is depicted in Figure 4. In addition to a more direct relationship between fragility and chewing, forage types differ by anatomical structure and digestion characteristics (Kammes and Allen, 2012), which likely also affect rate of NDF degradation, particle buoyancy in the rumen, passage rate of potentially degradable NDF, and also ruminal $\mathrm{pH}$. Admittedly the measure of ADF-to-NDF ratio is not specific, and the approach may be improved 
if a method to directly measure fragility is more widely adopted.

\section{Potential Explanatory Factors in Need of Further Research}

In this study, measures were taken to ensure that explanatory variables were also routinely generated and easily attainable in practice. Unfortunately, several factors that are likely to influence effectiveness of fiber and rumen conditions either are not traditionally reported in published studies or are difficult to measure. Future research should seek to more clearly define factors on rumen conditions such as (1) forage fragility and the nature of particle dynamics (Kennedy and Murphy, 1988; Bruining et al., 1998); (2) concentration and digestibility of ash-corrected NDF (Sniffen et al.,
1992), water-soluble carbohydrates, and soluble fiber (Hall et al., 1999); (3) rumen-degraded carbohydrates as affected by conservation method and by chemical or physical processing (Firkins, 2010); (4) use of ionophores (Firkins and $\mathrm{Yu}, 2015$ ); and (5) feeding management and behavior (Miller-Cushon and DeVries, 2010; Greter and Devries, 2011), which includes potential for influence by ionophores (Osborne et al., 2004) and direct-fed microbials (Seo et al., 2010). These should be addressed because aspects of feeding behavior and length of ingestive episodes may affect rate of ruminal passage and possibly interact with highly fermentable carbohydrates and reduce rumen $\mathrm{pH}$. Future research should also consider (6) associative rumen effects, such as VFA and ammonia absorption and urea secretion in rumen (Aschenbach et al., 2011), and (7) DCAD (Iwaniuk and Erdman, 2015).

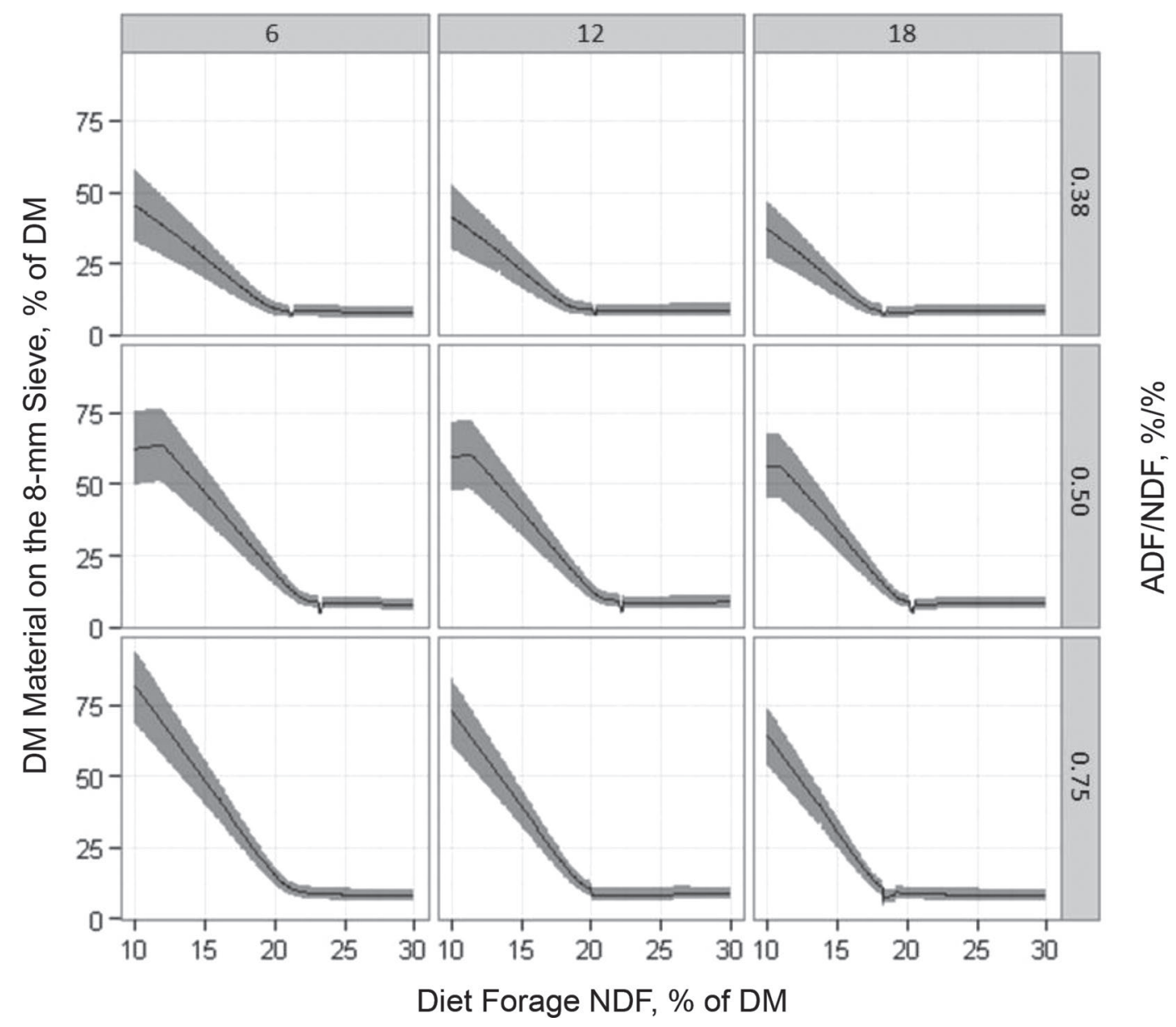

Figure 4. The recommended percentage of TMR (DM basis) retained on the $8-\mathrm{mm}$ sieve to achieve a target $\mathrm{pH}$ of 6.1 , as influenced by changing proportion of material on the 19-mm sieve (6,12 and 18\% DM) and ADF:NDF in the TMR. 


\section{CONCLUSIONS}

In this study, we used equations derived through a companion study's meta-analysis (White et al., 2017) to develop a system to estimate the combination of dietary physical and chemical characteristics that would maintain targeted ruminal $\mathrm{pH}$. The system employed an ensemble of models that were weighted and combined to generate more robust recommendations for the percentage of dietary DM material that should be retained on the 8-mm sieve of a PSPS given specific diet characteristics. As expected particle size, diet concentrations of starch and NDF, rumen-degraded NDF and starch, fNDF, and ADF-to-NDF ratio were identified as key explanatory variables. Feeding recommendations can be interpolated from tables and figures included in this work.

\section{ACKNOWLEDGMENTS}

The authors thank Keri Rogan (USDA-ARS, Madison, WI) and Jared Judy (University of Nebraska-Lincoln) for their efforts related to data entry. Funding for this project was also provided by Agriculture and Food Research Initiative Competitive Grant no. 2015-03656 from the USDA National Institute of Food and Agriculture (Washington, DC). Research was supported by state and federal funds appropriated to the University of Nebraska-Lincoln, Virginia Tech, and The Ohio State University and with funding from USDA-Agricultural Research Service (Washington, DC).

\section{REFERENCES}

Allen, M. S. 1997. Relationship between fermentation acid production in the rumen and the requirement for physically effective fiber. J. Dairy Sci. 80:1447-1462. https://doi.org/10.3168/jds.S0022 $-0302(97) 76074-0$.

ASABE. 2007. Method of determining and expressing particle size of chopped forage materials by screening, ANSI/ASAE S424.1. Am. Soc. Agric. Bio. Engin. St. Joseph, MI.

Aschenbach, J. R., G. B. Penner, F. Stumpff, and G. Gabel. 2011. ruminant nutrition symposium: Role of fermentation acid absorption in the regulation of ruminal pH. J. Anim. Sci. 89:1092-1107. https://doi.org/10.2527/jas.2010-3301.

Balch, C. C. 1971. Proposal to use time spent chewing as an index of the extent to which diets for ruminants possess the physical property of fibrousness characteristic of roughages. Br. J. Nutr. 26:383-392.

Beauchemin, K. A. 1991. Ingestion and mastication of feed by dairy cattle. Vet. Clin. North Am. Food Anim. Pract. 7:439-463. https:// doi.org/10.1016/S0749-0720(15)30794-5.

Bhandari, S. K., S. Li, K. H. Ominski, K. M. Wittenberg, and J. C. Plaizier. 2008. Effects of the chop lengths of alfalfa silage and oat silage on feed intake, milk production, feeding behavior, and rumen fermentation of dairy cows. J. Dairy Sci. 91:1942-1958. https://doi.org/10.3168/jds.2007-0358.

Bradford, B. J., and C. R. Mullins. 2012. Invited review: Strategies for promoting productivity and health of dairy cattle by feeding nonforage fiber sources. J. Dairy Sci. 95:4735-4746. https://doi .org/10.3168/jds.2012-5393.

Bruining, M., R. Bakker, J. van Bruchem, and S. Tamminga. 1998. Rumen digesta kinetics in dairy cows fed grass, maize and alfalfa silage: 1. Comparison of conventional, steady-state and dynamic methods to estimate microbial degradation, comminution and passage of particles. Anim. Feed Sci. Technol. 73:37-58. https://doi .org/10.1016/S0377-8401(98)00133-3.

Cotanch, K., R. J. Grant, and N. Y. Chazy. 2008. Fiber digestibility and forage fragility in dairy cattle. Pages 77-84 in Proceedings of the Cornell Nutrition Conference for Feed Manufacturers, Syracuse, NY. Cornell Univ., Ithaca, NY.

Dann, H. M., H. A. Tucker, K. W. Cotanch, P. D. Krawczel, C. S. Mooney, R. J. Grant, and T. Eguchi. 2014. Evaluation of lower-starch diets for lactating Holstein dairy cows. J. Dairy Sci 97:7151-7161. https://doi.org/10.3168/jds.2014-8341.

Danscher, A. M., S. Li, P. H. Andersen, E. Khafipour, N. B. Kristensen, and J. C. Plaizier. 2015. Indicators of induced subacute ruminal acidosis (SARA) in Danish Holstein cows. Acta Vet. Scand. 57: https://doi.org/10.1186/s13028-015-0128-9.

Dijkstra, J., J. L. Ellis, E. Kebreab, A. B. Strathe, S. López, J. France, and A. Bannink. 2012. Ruminal pH regulation and nutritional consequences of low pH. Anim. Feed Sci. Technol. 172:22-33. https:// doi.org/10.1016/j.anifeedsci.2011.12.005.

Ebert, E. E. 2001. Ability of a poor man's ensemble to predict the probability and distribution of precipitation. Mon. Weather Rev. 129:2461-2480

Einarson, M. S., J. C. Plaizier, and K. M. Wittenberg. 2004. Effects of barley silage chop length on productivity and rumen conditions of lactating dairy cows fed a total mixed ration. J. Dairy Sci. 87:2987-2996. https://doi.org/10.3168/jds.S0022-0302(04)73430 $-\mathrm{X}$

Farmer, E. R., H. A. Tucker, H. M. Dann, K. W. Cotanch, C. S. Mooney, A. L. Lock, K. Yagi, and R. J. Grant. 2014. Effect of reducing dietary forage in lower starch diets on performance, ruminal characteristics, and nutrient digestibility in lactating Holstein cows. J. Dairy Sci. 97:5742-5753. https://doi.org/10.3168/jds.2014 -7963 .

Firkins, J. L. 2010. Reconsidering rumen microbial consortia to enhance feed efficiency and reduce environmental impact of ruminant livestock production systems. Rev. Bras. Zootec. 39:445-457.

Firkins, J. L., and Z. Yu. 2015. Ruminant nutrition symposium: How to use data on the rumen microbiome to improve our understanding of ruminant nutrition. J. Anim. Sci. 93:1450-1470. https://doi .org/10.2527/jas.2014-8754.

Grant, R. 2010. Forage fragility, fiber digestibility, and chewing response in dairy cattle. Pages 27-40 in Proceedings of Tri-State Dairy Nutrition Conference, Fort Wayne, IN. The Ohio State University, Columbus.

Greter, A., and T. Devries. 2011. Effect of feeding amount on the feeding and sorting behaviour of lactating dairy cattle. Can. J. Anim. Sci. 91:47-54. https://doi.org/10.4141/CJAS10067.

Hall, M. B. 2015. Determination of dietary starch in animal feeds and pet food by an enzymatic-colorimetric method: collaborative study. J. AOAC Int. 98:397-409. https://doi.org/10.5740/jaoacint $.15-012$.

Hall, M. B., W. H. Hoover, J. P. Jennings, and T. K. M. Webster. 1999. A method for partitioning neutral detergent-soluble carbohydrates. J. Sci. Food Agric. 79:2079-2086. https://doi.org/10.1002/ (SICI)1097-0010(199912)79:15<2079:AID-JSFA502>3.0.CO;2-Z.

Harvatine, D. I. J. E. Winkler, M. Devant-Guille, J. L. Firkins, N. R St-Pierre, B. S. Oldick, and M. L. Eastridge. 2002. Whole linted cottonseed as a forage substitute: fiber effectiveness and digestion kinetics. J. Dairy Sci. 85:1988-1999. https://doi.org/10.3168/jds .S0022-0302(02)74275-6.

Heinrichs, J., and P. Kononoff. 2002. Evaluating particle size of forages and TMRs using the new Penn State Forage Particle Separator. Pa. State Univ. Coll. Agric. Sci. Coop. Ext. DAS 02-42. Pennsylvania State University, University Park. 
Iwaniuk, M. E., and R. A. Erdman. 2015. Intake, milk production, ruminal, and feed efficiency responses to dietary cation-anion difference by lactating dairy cows. J. Dairy Sci. 98:8973-8985. https:// doi.org/10.3168/jds.2015-9949.

Jarratt, P. 1967. An iterative method for locating turning points. Comput. J. 10:82-84. https://doi.org/10.1093/comjnl/10.1.82.

Kammes, K. L., and M. S. Allen. 2012. Nutrient demand interacts with grass particle length to affect digestion responses and chewing activity in dairy cows. J. Dairy Sci. 95:807-823. https://doi .org/10.3168/jds.2011-4588.

Kennedy, P. M., and M. R. Murphy. 1988. The nutritional implications of differential passage of particles through the ruminant alimentary tract. Nutr. Res. Rev. 1:189-208. https://doi.org/10.1079/ NRR19880014.

Kennedy, P. M., P. J. Toscas, M. J. Faddy, and D. J. Minson. 1997. Use of a multi-exponential model to assess the effect of fermentation in the reticulorumen on particle fragmentability as simulated from artificially macerating leaf and stem fractions of two tropical grasses. Anim. Feed Sci. Technol. 66:111-128. https://doi.org/10 1016/S0377-8401(96)01120-0.

Keunen, J. E., J. C. Plaizier, L. Kyriazakis, T. F. Duffield, T. M. Widowski, M. I. Lindinger, and B. W. McBride. 2002. Effects of a subacute ruminal acidosis model on the diet selection of dairy cows. J. Dairy Sci. 85:3304-3313.

Kmicikewycz, A. D., K. J. Harvatine, and A. J. Heinrichs. 2015. Effects of corn silage particle size, supplemental hay, and forageto-concentrate ratio on rumen $\mathrm{pH}$, feed preference, and milk fat profile of dairy cattle1. J. Dairy Sci. 98:4850-4868. https://doi .org $/ 10.3168 /$ jds.2014-9249.

Kmicikewycz, A. D., and A. J. Heinrichs. 2015. Effect of corn silage particle size and supplemental hay on rumen $\mathrm{pH}$ and feed preference by dairy cows fed high-starch diets. J. Dairy Sci. 98:373-385. https://doi.org/10.3168/jds.2014-8103.

Kononoff, P. J., and A. J. Heinrichs. 2003. The effect of reducing alfalfa haylage particle size on cows in early lactation. J. Dairy Sci. 86:1445-1457.

Kononoff, P. J., A. J. Heinrichs, and D. R. Buckmaster. 2003. Modification of the Penn State forage and total mixed ration particle separator and the effects of moisture content on its measurements. J. Dairy Sci. 86:1858-1863.

Krause, K. M., and D. K. Combs. 2003. Effects of forage particle size, forage source, and grain fermentability on performance and ruminal pH in midlactation cows. J. Dairy Sci. 86:1382-1397.

Lammers, B. P., D. R. Buckmaster, and A. J. Heinrichs. 1996. A simple method for the analysis of particle sizes of forage and total mixed rations. J. Dairy Sci. 79:922-928. https://doi.org/10.3168/ jds.S0022-0302(96)76442-1.

Leonardi, C., K. J. Shinners, and L. E. Armentano. 2005. Effect of different dietary geometric mean particle length and particle size distribution of oat silage on feeding behavior and productive performance of dairy cattle. J. Dairy Sci. 88:698-710.

Lin, L. I. 1989. A concordance correlation coefficient to evaluate reproducibility. Biometrics 45:255-268.

Maulfair, D. D., and A. J. Heinrichs. 2013. Effects of varying forage particle size and fermentable carbohydrates on feed sorting, ruminal fermentation, and milk and component yields of dairy cows1. J. Dairy Sci. 96:3085-3097. https://doi.org/10.3168/jds.2012-6048.

Meier, H. E. M., H. C. Andersson, B. Arheimer, C. Donnelly, K. Eilola, B. G. Gustafsson, L. Kotwicki, T.-S. Neset, S. Niiranen, J. Piwowarczyk, O. P. Savchuk, F. Schenk, J. M. Węsławski, and E. Zorita. 2014. Ensemble modeling of the Baltic Sea ecosystem to provide scenarios for management. Ambio 43:37-48. https://doi .org/10.1007/s13280-013-0475-6.

Mertens, D. R. 1997. Creating a system for meeting the fiber requirements of dairy cows. J. Dairy Sci. 80:1463-1481. https://doi.org/ 10.3168/jds.S0022-0302(97)76075-2.

Miller-Cushon, E. K., and T. J. DeVries. 2010. Feeding amount affects the sorting behavior of lactating dairy cows. Can. J. Anim. Sci. 90:1-7.
Mould, F. L., E. R. Ørskov, and S. O. Mann. 1983. Associative effects of mixed feeds. I. effects of type and level of supplementation and the influence of the rumen fluid $\mathrm{pH}$ on cellulolysis in vivo and dry matter digestion of various roughages. Anim. Feed Sci. Technol. 10:15-30. https://doi.org/10.1016/0377-8401(83)90003-2.

Norgaard, P. 1989. The influence of physical form of ration on chewing activity and rumen motility in lactating cows. Acta Agric. Scand. 39:187-202. https://doi.org/10.1080/00015128909438512.

NRC. 2001. National Research Council (U.S.), and Subcommittee on Dairy Cattle Nutrition, Nutrient Requirements of Dairy Cattle. 7th rev. ed. National Academy Press, Washington, DC.

Osborne, J. K., T. Mutsvangwa, O. Alzahal, T. F. Duffield, R. Bagg, P. Dick, G. Vessie, and B. W. McBride. 2004. Effects of monensin on ruminal forage degradability and total tract diet digestibility in lactating dairy cows during grain-induced subacute ruminal acidosis. J. Dairy Sci. 87:1840-1847.

Polikar, R. 2006. Ensemble based systems in decision making. IEEE Circuits Syst. Mag. 6:21-45. https://doi.org/10.1109/MCAS.2006 .1688199

Pollard, D., W. Chang, M. Haran, P. Applegate, and R. DeConto. 2016. Large ensemble modeling of the last deglacial retreat of the West Antarctic Ice Sheet: comparison of simple and advanced statistical techniques. Geosci. Model Dev. 9:1697-1723. https://doi .org/10.5194/gmd-9-1697-2016.

$\mathrm{R}$ Core Team. 2014. A language and environment for statistical computing. Version 3.1.0. R. Foundation for Statistical Computing, Vienna, Austria.

Robinson, P. H., and R. E. McQueen. 1997. Influence of level of concentrate allocation and fermentability of forage fiber on chewing behavior and production of dairy cows. J. Dairy Sci. 80:681-691. https://doi.org/10.3168/jds.S0022-0302(97)75987-3.

Roebber, P. J., D. M. Schultz, B. A. Colle, and D. J. Stensrud. 2004 Toward improved prediction: High-resolution and ensemble modeling systems in operations. Weather Forecast. 19:936-949.

Roman-Garcia, Y., R. R. White, and J. L. Firkins. 2016. Meta-analysis of postruminal microbial nitrogen flows in dairy cattle. I. derivation of equations. J. Dairy Sci. 99:7918-7931. https://doi.org/10 $.3168 /$ jds.2015-10661.

Sarhan, M. A., and K. A. Beauchemin. 2015. Ruminal pH predictions for beef cattle: Comparative evaluation of current models. J. Anim. Sci. 93:1741 https://doi.org/10.2527/jas.2014-8428.

Schwab, E. C., R. D. Shaver, K. J. Shinners, J. G. Lauer, and J. G. Coors. 2002. Processing and chop length effects in brown-midrib corn silage on intake, digestion, and milk production by dairy cows. J. Dairy Sci. 85:613-623.

Seo, J.-K., S.-W. Kim, M.-H. Kim, S. D. Upadhaya, D.-K. Kam, and J.-K. Ha. 2010. Direct-fed microbials for ruminant animals. Asianaustralas. J. Anim. Sci. 23:1657-1667.

Shi, Y., and P. J. Weimer. 1992. Response surface analysis of the effects of $\mathrm{pH}$ and dilution rate on Ruminococcus flavefaciens FD-1 in cellulose-fed continuous culture. Appl. Environ. Microbiol. 58:2583-2591.

Sniffen, C .J., J. D. O'Connor, P. J. VanSoest, D. G. Fox, and J. B. Russell. 1992. A net carbohydrate and protein system for evaluating cattle diets: II. Carbohydrate and protein availability. J. Anim. Sci. 70:3562-3577. https://doi.org/10.2527/1992.70113562x.

St-Pierre, N. R. 2007. Meta-analyses of experimental data in the animal sciences. Rev. Bras. Zootec. 36:343-358.

Sudweeks, E. M., L. O. Ely, D. R. Mertens, and L. R. Sisk. 1981. Assessing minimum amounts and form of roughages in ruminant diets: roughage value index system. J. Anim. Sci. 53:1406-1411.

Tsai, C. H., J. Kolibal, and M. Li. 2010. The golden section search algorithm for finding a good shape parameter for meshless collocation methods. Eng. Anal. Bound. Elem. 34:738-746. https://doi .org/10.1016/j.enganabound.2010.03.003.

Van Soest, P. J. 1994. Nutritional Ecology of the Ruminant, 2nd ed. Cornell University Press, Ithaca, NY.

Waldo, D. R., L. W. Smith, E. L. Cox, B. T. Weinland, and H. L. Lucas. 1971. Logarithmic normal distribution for description of 
sieved forage materials. J. Dairy Sci. 54:1465-1469. https://doi .org/10.3168/jds.S0022-0302(71)86048-4.

White, R. R., M. B. Hall, J. Firkins, and P. J. Kononoff. 2017. Physically adjusted neutral detergent fiber system for lactating dairy cow rations. I: Deriving equations that identify factors that influence effectiveness of fiber. J. Dairy Sci. 100:9551-9568. https:// doi.org/10.3168/jds.2017-12765.

White, R. R., Y. Roman-Garcia, and J. L. Firkins. 2016. Meta-analysis of postruminal microbial nitrogen flows in dairy cattle. II. Approaches to and implications of more mechanistic prediction. J. Dairy Sci. 99:7932-7944. https://doi.org/10.3168/jds.2015-10662.

Yang, W. Z., and K. A. Beauchemin. 2006. Physically effective fiber: Method of determination and effects on chewing, ruminal acidosis, and digestion by dairy cows. J. Dairy Sci. 89:2618-2633.

Yang, W. Z., and K. A. Beauchemin. 2007a. Altering physically effective fiber intake through forage proportion and particle length: Chewing and ruminal ph. J. Dairy Sci. 90:2826-2838. https://doi .org/10.3168/jds.2007-0032.

Yang, W. Z., and K. A. Beauchemin. 2007b. Altering physically effective fiber intake through forage proportion and particle length: Di- gestion and milk production. J. Dairy Sci. 90:3410-3421. https:// doi.org/10.3168/jds.2006-818.

Yang, W. Z., and K. A. Beauchemin. 2009. Increasing physically effective fiber content of dairy cow diets through forage proportion versus forage chop length: Chewing and ruminal ph. J. Dairy Sci. 92:1603-1615. https://doi.org/10.3168/jds.2008-1379.

Zebeli, Q., J. R. Aschenbach, M. Tafaj, J. Boguhn, B. N. Ametaj, and W. Drochner. 2012. Invited review: Role of physically effective fiber and estimation of dietary fiber adequacy in high-producing dairy cattle. J. Dairy Sci. 95:1041-1056. https://doi.org/10.3168/ jds.2011-4421.

Zebeli, Q., J. Dijkstra, M. Tafaj, H. Steingass, B. N. Ametaj, and W. Drochner. 2008. Modeling the adequacy of dietary fiber in dairy cows based on the responses of ruminal ph and milk fat production to composition of the diet. J. Dairy Sci. 91:2046-2066. https://doi .org $/ 10.3168 /$ jds.2007-0572.

Zhu, J. S., S. R. Stokes, and M. R. Murphy. 1997. Substitution of neutral detergent fiber from forage with neutral detergent fiber from by-products in the diets of lactating cows. J. Dairy Sci. 80:29012906. https://doi.org/10.3168/jds.S0022-0302(97)76255-6. 